\title{
Prática religiosa e criminalidade: um estudo de caso
}

\author{
Pery Francisco Assis Shikida \\ Helena Nickel \\ Josineide Aquino da Silva Amaral
}

\begin{abstract}
Resumo
O objetivo principal deste estudo é analisar quais variáveis influenciaram a prática religiosa de pessoas que cometeram delitos e suas motivações para o crime, a partir da aplicação de questionários e entrevistas, junto a condenados com penas alternativas, na cidade de Foz do Iguaçu, Paraná. Além da pesquisa de campo e análise descritiva dos dados, este estudo faz uso de uma regressão logística como modelagem econométrica. Os resultados indicam que as variáveis do modelo que influenciaram a prática religiosa das pessoas que cometeram delitos, antes de terem sido presas, foram: "harmonia familiar", "tem filhos", "religião católica" e "religião evangélica" - relação positiva; "ensino superior completo", "amasiado", "uso de bebida alcoólica" e "uso de drogas" - relação negativa. Este estudo de caso permite inferir que a pessoa religiosa praticante, com característica considerada dissuasória, não distinguiu valores ou princípios quando seu interesse financeiro prevaleceu em um ato ilegal.
\end{abstract}

Palavras-chave | Análise custo/benefício; criminalidade; Foz do Iguaçu; prática religiosa.

Classificação JEL | C40 K14 Z12

\section{Religious practice and criminality: a case study}

\begin{abstract}
The main objective of this study is to analyze the variables that influenced the religious practice of people who committed a crime, and their motivations for the crime, from the application of questionnaires and interviews with convicts in alternative sentences in the city of Foz do Iguaçu (Paraná). In addition to field research and descriptive data analysis, this study makes use of logistic regression as econometric modeling. As a result, the variables of the model that influenced their religious practice, who committed the crime before being arrested, were: "harmonic family", "have children", "catholic religion" and "evangelical religion" - positive relationship; "graduated", "cohabiting", "use of alcohol" and "use of drug" - negative relationship. The case study allows us to infer that this practitioner religious person, a characteristic considered to be dissuasive, did not distinguish values or principles when his/her financial interest prevailed in an illegal act.
\end{abstract}


Keywords | Cost/benefit analysis; criminality; Foz do Iguaçu; religious practice.

JEL Classification | C40 K14 Z12

\section{Práctica religiosa y criminalidad: un estudio de caso}

\section{Resumen}

El objetivo principal de este estudio es analizar qué variables influyeron en la práctica religiosa de las personas que cometieron delitos y sus motivaciones para el crimen, mediante la aplicación de cuestionarios y entrevistas a convictos con sentencias alternativas, en la ciudad de Foz do Iguazú, Paraná. Además de la investigación de campo y el análisis de datos descriptivos, este trabajo hace uso de la regresión logística como modelo econométrico. Los resultados indican que las variables de modelo que influyeron en la práctica religiosa de estas personas que cometieron delitos, antes de ser convictas, fueron: "armonía familiar", "tiene hijos", "religión católica" y "religión evangélica" - relación positiva; "educación superior completa", "amancebado", "consumista de alcohol" y "consumista de drogas" - relación negativa. Este estudio de caso nos permite inferir que esta persona religiosa, con una característica considerada disuasoria, no distinguió valores o principios cuando su interés financiero prevalecía en un acto ilegal.

Palabras clave | Análisis de costo/beneficio; criminalidad; Foz do Iguaçu; práctica religiosa.

Clasificación JEL | C40 K14 Z12

\section{Introdução}

Conforme legislação vigente no Brasil, a definição de crime é toda e qualquer ação que a lei impõe "pena de reclusão ou detenção, quer isoladamente, quer alternativa ou cumulativamente com a pena de multa; contravenção, a infração a que a lei comina, isoladamente, penas de prisão simples ou de multa, ou ambas [...]" (BRASIL, 2017, p. 485). De acordo com o Código Penal (CP) (BRASIL, 1940; 2017), a determinação do regime inicial de cumprimento da pena far-se-á com base nos critérios previstos em lei, dentre os quais: a) culpabilidade do réu; b) antecedente(s); c) conduta social; d) personalidade da pessoa; e) motivo(s) para o crime; f) circunstância(s) do delito; g) consequência(s) dessa atividade criminal; e h) comportamento da vítima.

Com efeito, quanto mais grave é o crime praticado, mais rigoroso é o tratamento direcionado ao réu (BRASIL, 2017). Assim, existe o regime fechado referente às condenações mais graves, destinado aos condenados com pena superior a oito anos ou para os condenados reincidentes cuja pena seja inferior a oito anos, porém 
superior a quatro; podendo a execução da pena ser em estabelecimento de segurança máxima ou média.

O regime semiaberto é aquele no qual o apenado possui condições de trabalho, sem ser potencialmente ofensivo para a ordem social, podendo trabalhar durante o dia, mas devendo recolher-se ao local de cumprimento da pena - que pode ser uma colônia agrícola, industrial ou estabelecimento similar - durante o período noturno. É aplicável ao condenado não reincidente (primário) cuja pena for superior a quatro e não exceda a oito anos (BRASIL, 1984; 2017).

O regime aberto é imposto a todo réu condenado a até quatro anos de prisão, desde que não reincidente. Neste caso, o apenado pode trabalhar durante os dias e recolher-se durante as noites em lugar determinado em sentença, podendo ser uma casa de albergado ou outro estabelecimento adequado - por exemplo, sua própria residência (BRASIL, 1984; 2017).

As penas privativas de liberdade substituídas por prestação de serviços à comunidade ou a entidades públicas e/ou prestação pecuniária possuem, em teoria, caráter pedagógico. Vale ressaltar, de acordo com o Código Penal (BRASIL, 1940; 2017), que a prestação de serviços à comunidade ou a entidades públicas é duplamente benéfica porque é uma forma de punição e de reeducação do sentenciado. É aplicável, de maneira substitutiva, às condenações maiores do que seis meses e não superior a quatro anos de privação da liberdade [conforme especificado na Lei N. 9.714, de 25 de novembro de 1998 (BRASIL, 1998)], podendo ser realizada em entidades assistenciais, hospitais, escolas, orfanatos e outros estabelecimentos congêneres, em programas comunitários ou estatais. As tarefas do condenado, entretanto, são atribuídas em consonância com suas aptidões, devendo ser cumpridas à razão de uma hora de tarefa por dia de condenação, fixadas para não prejudicar a sua jornada normal de trabalho.

Toda esta definição tem a ver com o que este artigo propõe, conquanto amiúde as redes de comunicação noticiam fatos relacionados à criminalidade alarmante no Brasil. Segundo levantamento do Departamento Penitenciário Nacional (DEPEN, 2019), no Brasil existiam 758.676 presos, dos quais 33,3\% aguardavam julgamento. Dados do Conselho Nacional de Política Criminal e Penitenciária (CNPCP, 2019, p. 73) apontam que estes presos seguem uma divisão aproximada de $1 / 3$ por "crimes praticados com violência ou grave ameaça, 1/3 crimes sem violência ou grave ameaça e $1 / 3$ relacionados ao tráfico de drogas”. Afora estes dados, a sensação de insegurança para o cidadão brasileiro, aliado ao fator impunidade, recrudesce a desconfiança da população em uma solução de curto prazo, deixando este cenário ainda mais temerário (AMARAL, 2019; OLINI et al., 2019).

Uma das formas de desestimular a criminalidade é a boa formação do cidadão no tripé família-escola-religião, considerada por Shikida (2005, 2010, 2020) como uma trava moral capaz de dissuadir atos ilícitos. Neste sentido, se há um fator que contribui para minimizar o crime, como a prática religiosa, por exemplo, este pode 
colaborar para a melhora do contexto do desenvolvimento de um país, juntamente com outras variáveis como o progresso na distribuição de renda (visando o desenvolvimento social), o avanço da democracia (visando o desenvolvimento no contexto político) etc. Daí a importância de se estudar os motivos que levam as pessoas que teoricamente possuem travas morais, como as praticantes de crenças religiosas, a migrarem para atividades ilegais.

Não há na literatura um trabalho que sustente, com evidências empíricas para uma amostra significativa, a relação entre a prática religiosa e a migração ao crime. Vale frisar que se entende por prática religiosa uma "atividade ritual por meio da qual as pessoas expressam de forma simbólica, através de sua conduta, o relacionamento com o mundo sagrado"; esta prática segue os códigos de procedimento da religião afim, conforme suas representações coletivas e organização social (CNFCP, 2021, p. 1). Apenas Shikida, Araujo Junior e Shikida (2005) observaram a importância da moral na forma de crenças religiosas, no estudo da ação de delinquentes com base em dados coletados via entrevistas em 262 detentos de estabelecimentos prisionais paranaenses.

Isto posto, o escopo principal deste estudo é analisar quais as variáveis que influenciaram na prática religiosa de pessoas que cometeram delitos, bem como suas motivações para o crime, a partir de aplicação de questionários e entrevistas em condenados com penas alternativas - prestação de serviços à comunidade e/ou prestação pecuniária (portanto, delitos considerados menos graves) - no âmbito da 4a. Vara da Justiça Federal de Foz do Iguaçu (Paraná). Além da pesquisa de campo e análise descritiva dos dados, este trabalho faz uso de uma regressão logística sobre as variáveis obtidas visando exatamente descobrir qual o perfil de praticantes de religião, mas que vieram a cometer delitos sendo, posteriormente, condenados por conta disso.

Este artigo contém cinco seções, incluindo esta introdução. Na sequência são expostas uma concisa revisão de literatura, a metodologia e os resultados e discussão. As considerações finais sumarizam este estudo.

\section{Revisão de literatura}

Conforme mencionado, esta seção será breve, não por negligência, mas porque as literaturas que destacam as características de pessoas praticantes de uma religião, antes de cometeram crimes e serem condenadas por isto, são muito escassas no Brasil. Neste contexto, optou-se por focar também alguns trabalhos que relacionam crime e religião.

Inicialmente cabe destacar, conforme dados do último Censo Demográfico realizado no Brasil (IBGE, 2010), que a religião católica apostólica romana é a que apresentou a maior participação percentual de adeptos no País $(64,4 \%)$, seguida da 
evangélica (22,1\%), sem religião $(8,0 \%)$, espírita $(2,0 \%)$ e outras $(3,4 \%)$. Tal cenário se deve, em parte, ao forte legado da colonização portuguesa, conquanto o catolicismo foi a religião oficial do Estado até a Constituição Republicana de 1891, que garantiu o direito à liberdade religiosa a partir desse momento (SANTOS; NEVES; GOUVEIA, 2006).

Não obstante, tendo como pressuposto que a violência dos criminosos é um problema social e econômico que pode ser estudado mediante modelo do bomo economicus maturus, Shikida, Araujo Junior e Shikida (2005) - a partir do modelo de Frey (1997) adaptado ao comportamento criminoso violento - testaram a importância da moral (na forma de crenças religiosas) sobre a ação de criminosos. Para tanto, foi utilizada uma amostra de dados de entrevistas com presos(as) da Penitenciária Central, Estadual e Feminina de Piraquara (Paraná). Os resultados "sugerem que indivíduos que são, de alguma forma, religiosos, têm menos tendência a se envolver em crimes violentos, ou seja, 'restrições' morais fazem alguma diferença", sendo mais propensos ao uso da violência os jovens do sexo masculino, que possuíam arma de fogo, não acreditam na Justiça e possuíam parceiro no crime (SHIKIDA; ARAUJO JUNIOR; SHIKIDA, 2005, p. 422).

Tendo como intento compreender o efeito da religiosidade no crime, Heaton (2006) analisou, por meio de modelagem econométrica de equações simultâneas, 3.008 municípios dos Estados Unidos, examinando também a variação na incidência de crimes antes e depois da Páscoa. Não se constatou relação estatisticamente significativa entre a religião e o crime contra propriedade ou crime violento. Analisando especificamente a Páscoa, não houve evidências de uma diminuição do crime após este feriado religioso. Porém, segundo o autor, sugere-se que quem praticou o crime apresentaria algum sentimento de culpa pelo seu ato ilegal, vindo a não frequentar mais a sua religião. Nesse sentido, pode-se dizer que a crença religiosa é afetada pelo crime de forma negativa.

Neste contexto, Murta, Araujo Junior e Shikida (2008) estudaram, a partir de um estudo econométrico baseado no modelo de Heaton (2006), a relação entre o nível de religiosidade e a criminalidade para o contexto brasileiro. Como conclusão, sugere-se "[...] a existência de uma relação negativa entre o nível de religiosidade de um determinado estado/município e sua taxa de homicídio, o que é uma evidência a favor do argumento da religião como trava moral às ações dos criminosos" (MURTA; ARAUJO JUNIOR; SHIKIDA, 2008, p. 102). Deriva-se do trabalho ora reportado o fato de que a religião pode ser um complemento às políticas públicas que objetivam reduzir a criminalidade no Brasil, especialmente de crimes violentos.

Loureiro et al. (2009) testaram em seu artigo se características referentes aos aspectos socioeconômicos, herança familiar, interação social, hábitos e costumes, incluindo práticas religiosas, explicam diferenças entre prisioneiros não violentos e violentos. Para tanto, foi utilizada uma amostra de dados feita exclusivamente com a história de condenados da Penitenciária Estadual da Papuda (Brasília, DF), fazendo uso 
também de uma modelagem econométrica tipo Probit. Como corolário, as questões econômicas são as principais variáveis que incentivam a prática de crimes não violentos, enquanto que fatores relacionados à herança familiar contribuem para reduzir a prática de crimes violentos. Contudo, a variável de interesse nesta revisão, frequentar uma religião ${ }^{1}$, não foi estatisticamente significativa.

O trabalho de Ribeiro e Minayo (2014) consistiu em fazer uma importante revisão de artigos sobre a religião e a saúde, ressaltando também a prevenção da violência e a recuperação de pessoas envolvidas com o mundo do crime. Inicialmente as autoras definem religião como um sistema de crenças que forma as relações dos grupos sociais com um ser maior, um ser transcendental. Seus resultados realçam:

[...] a função do grupo e o papel da religião na reabilitação de pessoas, na prevenção do envolvimento com a criminalidade, em orientações correcionais, e em territórios de iniquidade social. É realizado um debate acerca dos principais temas encontrados, destacando a multiplicidade de papéis da religião, sua atuação junto às pessoas encarceradas, como base de apoio e controle social e sua influência na promoção da saúde mental e da qualidade de vida. A relação entre religião e esfera pública é discutida, assinalando o papel de grupos religiosos e a fragilidade do Estado em fornecer políticas públicas básicas à população. Apesar de apontarem o papel exitoso da religião na prevenção da violência e na reabilitação de pessoas, alguns estudos põem em xeque esta relação e destacam conflitos entre os conceitos utilizados e os resultados obtidos (RIBEIRO; MINAYO, 2014, p. 1773).

Dessa forma, para Ribeiro e Minayo (2014) é complexa a relação entre religião, violência e criminalidade, sendo complicado aferir uma inferência derradeira quanto à efetividade da religião e do papel das igrejas no tocante à minimização da criminalidade.

Schlemper (2018), em trabalho que analisou as circunstâncias socioeconômicas da escolha ocupacional entre o setor lícito e ilícito para 209 pessoas condenadas ou presas em regime provisório (em seis estabelecimentos prisionais paranaenses e gaúchos), também trouxe conclusões sobre a prática religiosa e o crime. De acordo com este autor, 100\% dos seus pesquisados disseram acreditar em Deus. Desse total, 52\% disseram não praticar nenhuma crença religiosa, enquanto $48 \%$ alegaram praticar suas crenças religiosas. Em seu modelo econométrico (Logit), a variável ter religião ou mesmo praticá-la não foi significativa como característica determinante para uma pessoa jovem não migrar para o crime. Outrossim, há evidências estatísticas de que os entrevistados que cometeram crimes, em sua maioria,

\footnotetext{
1 Faz-se necessário relatar que a frequência das práticas religiosas é distinta, variando conforme os diferentes procedimentos e especificidades de cada crença (SANTOS, 2020).
} 
ponderaram o benefício da atividade ilegal vis-à-vis seu custo, não se atendo para nenhum tipo de trava moral (como família, escola e/ou religião) no momento de delinquir. Pensaram mais no ganho pecuniário do que em qualquer outro fator dissuasório.

Amaral (2019), ao procurar identificar e analisar os determinantes das mulheres que migraram para o crime de tráfico de drogas, que estavam cumprindo pena ou aguardando julgamento na Unidade Prisional Feminina de Rio Branco (Acre), também não constatou fatores que deveriam funcionar como trava moral para que essas mulheres não entrassem no tráfico de drogas. Ou seja, nesse estudo não foram significativas no modelo econométrico (Logit) questões como o bom exemplo da tríade família, religião e educação. Porém, de igual forma ao trabalho de Schlemper (2018), mas, especificamente em se tratando de uma amostra para o sexo feminino, a autora constatou que de suas 146 entrevistadas, daquelas que afirmaram ter uma religião, $37,3 \%$ não eram praticantes, enquanto $62,7 \%$ se declararam praticantes. Novamente, a relação entre custo e benefício financeiro da atividade delituosa, respondida nesse caso somente pelas mulheres, mostrou qual foi a principal motivação para a migração ao crime, conquanto "[...] 63,7\% declararam que o benefício foi maior que o custo, $14,4 \%$ disseram que benefício foi menor que o custo, $4,1 \%$ afirmaram que benefício foi igual ao custo e $17,8 \%$ não responderam" (AMARAL, 2019, p. 105). Como resultado, para expressiva parcela dessas mulheres, os retornos econômicos foram maiores do que os custos do delito, o que significa dizer que o crime está, lamentavelmente, compensando também para o sexo feminino no caso em epígrafe.

Por último, mas não menos importante, há dificuldades de se apontar a variável religião para a motivação ou impedimento de práticas criminais no Brasil. Não obstante, citam-se três estudos - dentre vários - que apontam a relação entre religião e criminalidade. Sobre isto, Marques (2013, p.17) apresentou em seu trabalho um personagem como "exemplo de transformação no interior do pentecostalismo e da conversão", em que "a sua dupla irmandade (irmão do PCC e irmão da igreja) revelou implicações teóricas e práticas no campo de pesquisa empírica". Cunha (2008, p. 42) argumenta que alguns traficantes "buscam igrejas para congregarem mesmo ainda participando das atividades criminosas na favela, [...] outros buscam nas igrejas ou na rede evangélica formada por 'irmãos na fé' uma proteção forte, espécie de 'fechamento de corpo"'. Já Morellato (2019, p. 35) destacou que a fé dos traficantes está inserida dentro de uma intrincada realidade social, em que "os encaixes nas categorias 'fiel' e 'bandido' podem ser antagônicos, mas não são totalmente excludentes". Assim, a união da religiosidade com a criminalidade, embora atípica, tem possibilitado a formação de novos perfis de bandidos.

Isto posto, a seção seguinte trata da metodologia seguida por este estudo. 


\section{Metodologia}

Esta seção contém duas partes imbricadas entre si, uma primeira abarca o tipo de estudo e a busca de dados primários, enquanto a segunda especifica o modelo utilizado.

Vale realçar que esta pesquisa se fundamenta em um estudo de caso - sobre isto, ver: Gil (2000) e Yin (2015). Como foco em dados primários, visando riqueza empírica, foi escolhido analisar apenados da 4a. Vara da Justiça Federal de Foz do Iguaçu, Seção Judiciária do Paraná, cujas penas privativas de liberdade foram substituídas por prestação de serviços à comunidade ou a entidades públicas e/ou prestação pecuniária, mediante aplicação de questionários/entrevistas (Anexo A). Cumpre destacar que a obtenção desse tipo de dados não é simples, haja vista a colaboração institucional necessária a fortiori. Também há necessidade de colaboração dos respondentes de modo voluntário, seguindo procedimento de um termo de consentimento livre e esclarecido.

Esta pesquisa de campo ocorreu durante o primeiro semestre de 2019 na própria sede da 4a. Vara da Justiça Federal de Foz do Iguaçu, sendo aplicados questionários seguidos de entrevistas em 272 pessoas que prestavam serviços à comunidade e/ou prestação pecuniária, como pena alternativa à privação de liberdade. $O$ total de apenados aptos a participar dessa pesquisa foi de 300 pessoas, o que corresponde dizer que a amostra obtida correspondeu a 90,7\% do total de respondentes, índice muito satisfatório.

O questionário utilizado (Anexo A) foi baseado em estudo pioneiro de Borilli (2005), que recebeu modificações e avanços em Schlemper (2018), sendo adaptado para atender aos objetivos do presente trabalho. Este instrumento de coleta de dados está dividido em quatro blocos:

- Dados gerais: desenvolve uma caraterização geral do entrevistado nos aspectos pessoais, demográficos e comportamentais;

- Tipologia e aspectos econômicos do crime: além de tipificar o crime, cometido por cada apenado e sua motivação, este bloco de questões aborda os aspectos de custo e retorno do crime, elementos fundamentais da teoria econômica do crime de Becker (1968);

- Maioridade penal: confronta a opinião dos entrevistados com relação aos aspectos da maioridade penal no Brasil (18 anos de idade) e a possibilidade de sua (controversa) redução para 16 anos;

- Outras questões: trata-se da percepção dos pesquisados em relação à atuação das facções/organizações criminosas e, também, sobre o mercado de drogas ilícitas e sua influência no mundo do crime (embora distantes do eixo principal da 
presente pesquisa, tais perguntas permitem revelar um quadro melhor do entrevistado).

Salienta-se que o instrumento de coleta dos dados utilizado é componente de um projeto maior, aprovado no âmbito do Conselho Nacional de Desenvolvimento Científico e Tecnológico e autorizado pela $4^{\mathrm{a}}$ Vara da Justiça Federal de Foz do Iguaçu (Paraná).

Conforme um dos focos deste trabalho, na estatística descritiva dos dados obtidos será apresentada apenas uma caracterização dos entrevistados em termos de perfil sociodemográfico, principais tipos de crime, motivação da migração para o mercado ilícito e relação custo/benefício da atividade criminosa.

Ademais, a presente pesquisa optou por um modelo econométrico de probabilidade linear, que tem como característica principal possuir a variável dependente qualitativa (uma dummy - binária). A variável é binária quando sua resposta se enquadra em apenas duas possibilidades de resposta, ocorrência ou não do evento. A variável dependente será SIM (1) no caso de a pessoa ter praticado uma religião antes de efetuado um crime, sendo posteriormente condenada; e será NÃO (0) no caso da pessoa não ter praticado uma religião antes de ter efetuado um crime, sendo posteriormente condenada.

Segundo Wooldridge (2017), o modelo de probabilidade linear possui a limitação de produzir valores inferiores a zero ou superiores a um, mas que pode ser corrigido com a adoção de uma função logística. Atendendo esse requisito, optou-se nesta pesquisa pela função Logit. Esta opção se justifica devido sua simples operacionalidade e eficácia na resposta econométrica. Além disso, citam-se diversos trabalhos (em estudos similares), que utilizaram esta função: Gonçalves Júnior e Shikida (2013); Schlemper (2018); Amaral (2019) etc.

Gujarati e Porter (2011) apresenta assim a equação do Logit.

$$
L_{i}=1_{n}\left(\frac{P_{i}}{1-P_{i}}\right)=\beta_{0}+\beta_{1} X_{1}+\cdots \beta_{k} X_{k}+\mu_{i}
$$

Em que:

$L$ é a função de distribuição logística;

$P_{i}$ é a probabilidade de ocorrência do evento;

$1-P_{i}$ é a probabilidade de não ocorrência do evento;

$\beta$ representa o vetor de parâmetros (conjunto de variáveis explicativas);

$X$ representa a matriz das características consideradas relevantes para estimar a probabilidade de ocorrência do evento; e, 
$\mu$ é o erro aleatório.

Sendo a probabilidade de ocorrência do fato $P_{i}$ representada por:

$$
P_{i}=\frac{1}{1+e^{-\left(\beta_{0}+\beta_{1} X_{1}+\cdots \beta_{k} X_{k}\right)}}
$$

E a probabilidade de não ocorrência do fato $P_{i}$ representada pela equação:

$$
1-P_{i}=\frac{e^{-\left(\beta_{0}+\beta_{1} X_{1}+\cdots \beta_{k} X_{k}\right)}}{1+e^{-\left(\beta_{0}+\beta_{1} X_{1}+\cdots \beta_{k} X_{k}\right)}}
$$

A estimação do Logit, segundo Wooldridge (2017) ocorreu pelo Método de Máxima Verossimilhança (MMV), expresso por Gujarati e Porter (2011) da seguinte forma:

$$
L=\prod \frac{e^{-X_{i} \beta}}{1+e^{-X_{i} \beta}} \prod \frac{1}{1+e^{-X_{i} \beta}}
$$

As variáveis explicativas significativas foram determinadas pelo método Binary Choice Logit estimado no software Eviews.

Com as variáveis explicativas definidas, focou-se na elaboração do modelo estimado, realizando o Teste de multicolinearidade, Teste de Hosmer e Lemeshow (2000) e Teste Wald.

Apresentada esta metodologia, a seção seguinte trata dos resultados e discussão.

\section{Resultados e discussão}

Os resultados da pesquisa são apresentados primeiramente sob a forma de frequências das respostas (estatística descritiva), conforme questionário aplicado aos pesquisados, ressaltando o perfil sociodemográfico, principais tipos de crime, motivação da migração para o mercado ilícito e relação custo/benefício da atividade criminosa. A análise econométrica encerra o presente estudo e discussão.

Conforme salientado anteriormente, foram aplicados 272 questionários nos apenados entrevistados. O perfil sociodemográfico dos apenados pode ser assim descrito: maioria homem (87,5\%); amasiado (46\%), de cor branca $(72,4 \%)$; natural do Paraná (71,3\%), com faixa etária considerada jovem (entre 18 e 33 anos, 
perfazendo 55,5\%); de origem urbana (81,3\%); possuem ensino fundamental na faixa do completo e incompleto $(47,1 \%)$; moravam junto com esposa e filhos $(53,7 \%)$; e viviam em harmonia familiar ${ }^{2}(87,1 \%)$. Em relação ao antecedente criminal na família, 70,6\% disseram que não havia esse tipo de antecedente e 29,4\% relataram algum familiar com antecedente criminal. Desses entrevistados, 53,3\% estavam trabalhando e ganhavam entre um e quatro salários-mínimos. Em relação à vida pregressa, a maioria fazia uso de bebida alcóolica $(55,5 \%)$, porém, não fumava $(73,5 \%)$ nem usava drogas ilícitas $(94,9 \%)$.

Foi perguntado se o apenado acreditava em Deus, como resposta 99,6\% disseram que sim. As religiões com maiores frequências foram: católica (59,2\%); evangélica $(32,0 \%)$; muçulmana $(1,1 \%)$; espírita $(0,7 \%)$; protestante $(0,4 \%)$; e sem religião $(6,6 \%)$. Dos que afirmaram ter uma religião, $58,8 \%$ disseram praticá-la, ao revés, $41,2 \%$ não praticavam a religião que declararam ter.

Cotejando os resultados dessa amostra - frisa-se, de um determinado caso municipal e de uma vara federal -, nota-se que a maioria também foi católica $(59,2 \%$ na amostra pesquisada contra $64,4 \%$ apontada pelo Censo), seguida da evangélica $(32,0 \%$ contra $22,1 \%)$, sem religião $(6,6 \%$ contra $8,0 \%)$ e espírita $(0,7 \%$ contra 2,0\%). A distinção foi o percentual dos muçulmanos na amostra local, fato este pertinente, pois, conforme Berger e Fonseca (2019), o município de Foz do Iguaçu tem uma das maiores comunidades árabe-muçulmanas do Brasil.

Sobre os crimes cometidos pelos pesquisados, concentrados em delitos de natureza econômica (cuja finalidade maior é a obtenção de lucro, e sendo crimes da alçada da $4^{a}$ Vara da Justiça Federal de Foz do Iguaçu), tendo em vista que o entrevistado pode ter cometido mais de um crime diferente, o contrabando - importar ou exportar mercadoria proibida (em sua maioria de cigarro) - teve $54,4 \%$ de incidência, sendo o mais praticado. Nessa sequência tem-se: o descaminho $(32,0 \%)$, o tráfico de drogas $(6,6 \%)$ e a sonegação fiscal $(6,6 \%)$. O delito de descaminho está descrito no art. 334 do Código Penal, quando "iludir, no todo ou em parte, o pagamento de direito ou imposto devido pela entrada, pela saída ou pelo consumo de mercadoria" (BRASIL, 2017, p. 548). O ato ilícito de contrabando está no art. 334-A desse Código.

A Tabela 1 detalha as principais motivações para a prática do crime pelos entrevistados (o percentual total supera os 100\% devido à observância de mais de uma resposta para um mesmo respondente). A principal motivação para o crime, frisa-se, de natureza econômica, está relacionada com o bloco de ideias de ganho fácil/indução de amigos/cobiça, ambição, ganância/inveja/manter o status (45,6\%).

\footnotetext{
2 A expressão "vivia em harmonia familiar" é resultado de um complexo contexto de relacionamento que cada pessoa estabelece dentro do coletivo intrafamiliar em que vive. Por conseguinte, é uma categoria passível de múltiplas interpretações. Entrementes, este trabalho procurou tão somente captar o entendimento idiossincrático de cada pesquisado sobre se vivia (ou não) com essa tipificação de sentimento.
} 
Ajudar no orçamento familiar, pois estava desempregado, teve a ocorrência de $34,6 \%$, seguida pela dificuldade financeira/endividamento $(25,4 \%)$ e ajudar no orçamento familiar, mas estando empregado $(15,4 \%)$. As demais ocorrências ficaram abaixo da casa dos dois dígitos.

\section{Tabela 1 - Quais os motivos da prática criminosa}

\begin{tabular}{lc}
\hline Motivo para a prática da atividade criminosa & \% de ocorrência \\
\hline Ideia de ganho fácil/indução de amigos/cobiça, ambição, & 45,6 \\
ganância/inveja/manter o status & 34,6 \\
Ajudar no orçamento familiar/estava desempregado & 25,4 \\
Dificuldade financeira/endividamento & 15,4 \\
Ajudar no orçamento familiar/estava empregado & 4,0 \\
Falta de estrutura familiar/inconsequência e desejo de aventura & 3,7 \\
Sem informação (não sabia que era crime) & 2,6 \\
Diz-se inocente & 0,4 \\
Manter o sustento e vício & 1,1 \\
Motivos fúteis (embriaguez e falta de perspectiva) & 1,1 \\
Sem resposta & 1,1 \\
\hline
\end{tabular}

Fonte: Resultados da pesquisa (2020).

Apresenta-se nesta etapa da análise descritiva a relação do custo e benefício na ação criminosa de cada entrevistado. Considera-se como ganhos na atividade ilícita todo o montante financeiro auferido com este tipo de ação, já os custos são aqueles que o respondente julgar tê-los com o ato ilegal. $\mathrm{Na}$ entrevista, tanto o benefício como o custo foram perguntados de tal forma que se pudesse realizar uma avaliação em escala de grandeza de zero a nove (em relação ao benefício, zero quando foi considerado nulo e nove quando foi máximo; para o custo, zero quando foi considerado nulo e nove quando foi máximo). Ambas as escalas foram utilizadas para mensurar a prática do crime, haja vista não ser recomendável indagar sobre qual foi a monta financeira obtida com o contrabando, tráfico etc., nem o seu custo, para esse tipo de público (sobre isto, ver: BORILLI, 2005; SHIKIDA, 2010; SCHLEMPER, 2018 e AMARAL, 2019).

Ao questionar os apenados sobre a relação do custo e benefício da atividade criminosa, ficou evidente que o benefício foi maior que o custo para $72,8 \%$ dos pesquisados. O custo foi maior que o benefício em $4,8 \%$ dos casos, custo igual ao benefício em $16,9 \%$, sendo que não souberam responder $5,5 \%$.

Seguindo resultados similares de estudos realizados por Shikida (2005; 2010; 2020), Schlemper (2018) e Amaral (2019), para a maioria dessas pessoas entrevistadas os retornos econômicos também foram maiores do que os custos. Isto quer dizer que o crime continua - em outro espaço geográfico, em outro tempo, com tipologias de 
crimes considerados "menos graves", mas com o mesmo fito de lucratividade financeira - lamentavelmente, compensando! Loureiro et al. (2009) também concluíram que as questões econômicas são as principais variáveis que incentivam a prática de crimes não violentos, como os crimes de natureza lucrativa por exemplo.

Como inovação desta pesquisa, esses crimes de menor potencial ofensivo que cominam penas alternativas apresentaram, em média, um resultado líquido econômico menor vis-à-vis os outros delitos de maior potencial, como no caso do tráfico de drogas ou roubo. Desse modo, a lucratividade da prática ilícita, sem teor de causalidade, é maior quando o risco da punição é elevado (SCHLEMPER, 2018; SHIKIDA, 2020).

Quanto aos resultados econométricos, primeiramente cabe citar que os testes de robustez do modelo se apresentaram adequados, sendo as variáveis que deram significância estatística — portanto, que influenciaram na prática religiosa dessas pessoas que cometeram delitos, antes delas serem detidas e condenadas - expostas na Tabela 2.

Tabela 2 - Parâmetros estimados do Logit e efeito marginal

\begin{tabular}{lcccc}
\hline Variáveis & Parâmetros B & $\begin{array}{c}\text { Desvio } \\
\text { padrão }\end{array}$ & p-valor sig. & $\begin{array}{c}\text { Efeito } \\
\text { marginal }\end{array}$ \\
\hline Uso de bebida alcoólica* & $-0,6134$ & 0,2852 & 0,0315 & $-14,8$ \\
Religião Católica** & 1,3144 & 0,5027 & 0,0089 & 31,7 \\
Uso de drogas** & $-2,1381$ & 0,8124 & 0,0085 & $-51,5$ \\
Evangélica* & 1,0223 & 0,5257 & 0,0518 & 24,6 \\
Harmonia familiar* & 1,0483 & 0,4217 & 0,0129 & 25,3 \\
Tem filhos** & 0,9180 & 0,2855 & 0,0013 & 22,1 \\
Amasiado* & $-0,6769$ & 0,2921 & 0,0205 & $-16,3$ \\
Ensino superior** & $-1,3667$ & 0,4926 & 0,0055 & $-32,9$ \\
\hline
\end{tabular}

* Variáveis significativas a $5 \%$; ** foram significativas a $1 \%$.

Fonte: Resultados da pesquisa (2020).

Baseado nos efeitos marginais da Tabela 2, é possível aferir a probabilidade de uma pessoa com determinado perfil ter praticado sua religião antes de ter efetuado um crime, sendo posteriormente condenada. Cabe destacar que as interpretações dos efeitos marginais foram elaboradas em pontos percentuais (p.p.).

Duas variáveis com sinais positivos, "harmonia familiar" e "tem filhos" têm, em média e respectivamente, 25,3 e 22,1 pontos percentuais (p.p.) de probabilidade dessa pessoa indagada estar praticando uma determinada religião vis-à-vis uma que não esteja praticando a religião que professou ter. Com certeza, estas duas variáveis que retratam uma família estruturada e que tem filhos, teoricamente falando, 
condizem com a prática religiosa mais efetiva. Para Becker, Maestri e Bobato (2015), o bom exemplo de um contexto familiar harmônico e da composição estrutural de pais e filhos(as) pode colaborar na transmissão de valores religiosos, reportando-se às concepções de pertencimento religioso e/ao fortalecimento da fé. De acordo com os autores supracitados, nos resultados de sua pesquisa há aderência ao movimento religioso como uma rede de apoio social e afetiva, possibilitando mudanças no subsistema familiar filial e conjugal e, também, no envolvimento parental e nas práticas educativas. Ou seja, a família, ao transmitir aos filhos os princípios da prática religiosa, entende isto como um aspecto importante para o próprio relacionamento familiar, e não somente para a formação espiritual de seus componentes.

As outras duas variáveis com sinais positivos, "religião católica" e "religião evangélica" apresentaram, em média e respectivamente, 31,7 e 24,6 p.p. de probabilidade dessa pessoa indagada estar praticando as religiões supracitadas em cotejo com a pessoa que não esteja praticando a religião que professou ter (no presente estudo seriam as religiões muçulmana, espírita e protestante). Contudo, de fato, as maiores representações religiosas convergem para o catolicismo e para os evangélicos, com menos frequência das outras crenças.

Já as outras quatro variáveis constantes na Tabela 2 que resultaram em significância estatística, apresentaram efeito marginal com sinal negativo ("uso de bebida alcoólica", "uso de drogas", "amasiado" e "ensino superior completo"), apontando para uma direção contrária à prática religiosa desses pesquisados. Isto denota que quanto maior a escolaridade (nesse caso, "ensino superior completo", com menos 32,9 p.p. de probabilidade), se a pessoa é "amasiada" (menos 16,3 p.p. de probabilidade), faz "uso de bebida alcoólica" (menos 14,8 p.p. de probabilidade) ou "uso de drogas" (menos 51,5 p.p. de probabilidade), sua prática religiosa tende a não ser efetiva conforme estas interpretações dos efeitos marginais. Destarte, estas características realçadas influenciam, frisa-se, negativamente na prática religiosa.

De fato, qualquer vício é uma oposição às travas morais conforme salienta Shikida (2005, 2010, 2020), Schlemper (2018) e Amaral (2019), e para a prática religiosa isto não seria diferente, de modo que quanto maiores os vícios, menores serão as chances de uma pessoa praticar uma religião. Ressalta-se que o uso de drogas apresentou o maior efeito marginal de todas as variáveis, para o sinal positivo ou negativo.

Sobre a variável pessoa ser amasiada, isto aponta para o fato de quem não casa em uma religião tende, a priori, a ter sua prática religiosa menor. A despeito do Código Civil reconhecer "como entidade familiar a união estável entre o homem e a mulher, configurada na convivência pública, contínua e duradoura e estabelecida com o objetivo de constituição de família" (BRASIL, 2002, p. 1), a própria palavra "amasiado" é algo que soa pejorativamente (sua origem vem do latim amasia, significando amante). Do ponto de vista de alguns credos religiosos, um casal 
amasiado vive uma união conjugal ilegítima, estando amancebado ou juntado ou amigado - ambos sinônimos de amasiado (O QUE É AMASIADO?, 2020).

Muito embora a religião exerça um papel na promoção de valores como caridade, perdão, solidariedade, compaixão etc., podendo contribuir para uma maior coesão social e apoio mútuo (SILVA, 2008), o fato de o curso superior completo estar negativamente relacionado com prática religiosa (nesta pesquisa), indica que este tipo de entrevistado é mais propenso a questionar o papel da prática religiosa. Ressalta-se, contudo, que isto não significa que esta pessoa se opõe à religião, e sim que não a pratica vis-à-vis o contingente de outros níveis de escolaridade.

Considerando as variáveis do modelo cujos resultados deram significância estatística, pode-se dizer que as características que influenciaram na prática religiosa desses pesquisados antes de cometeram delitos, sendo posteriormente condenados, foram: "harmonia familiar", "tem filhos", "religião católica" e "religião evangélica" - relação positiva; "ensino superior completo", "amasiado", "uso de bebida alcoólica" e "uso de drogas" - relação negativa.

Em suma, considerando todas as variáveis significativas retratadas na Tabela 2 e estimando o modelo final a partir da equação 2 (que mostra a probabilidade associada à ocorrência do evento de interesse), tem-se 59,5\% de probabilidade de que estas características sejam determinantes para que a pessoa entrevistada neste estudo tenha a prática religiosa, mesmo tendo cometido crime(s), sendo condenada por este ilícito.

Vale destacar que o instrumento de coleta dos dados utilizado é componente de um projeto maior, aprovado no âmbito do Conselho Nacional de Desenvolvimento Científico e Tecnológico (CNPq), com foco na economia do crime. Certamente outras perguntas/variáveis poderiam contribuir para aumentar o score da probabilidade dessa prática religiosa pesquisada (por exemplo, número médio de dias frequentados na igreja, se houve empatia com o pastor/padre, assiduidade quanto ao dízimo ou outra taxa pecuniária destinada à igreja etc.). Todavia, não foram feitas tais perguntas, o que justifica a existência do efeito marginal geral na ordem de 59,5\% de probabilidade, aceitável também.

Apesar disso, esta pesquisa permite inferir que uma pessoa religiosa praticante, característica esta considerada dissuasória, não distinguiu valores ou princípios quando seu interesse financeiro prevaleceu em um ato ilegal. Ou seja, o dinheiro/lucro contou mais! Prova disso foi a racionalidade econômica da análise custo/benefício da ação ilegal praticada, pari passu às motivações para a migração ao crime terem sido, mormente, devido desejo desmedido pelo dinheiro e/ou bens materiais - sendo que $72,8 \%$ dos pesquisados apontaram lucro com o crime realizado. 


\section{Considerações finais}

Este artigo teve como intento principal analisar quais as variáveis que influenciaram na prática religiosa de pessoas que cometeram delitos, bem como suas motivações para o crime, a partir de aplicação de questionários e entrevistas em condenados com penas alternativas. Trata-se, pois, de um estudo de caso para apenados de prestação de serviços à comunidade e/ou prestação pecuniária, no âmbito da $4^{\mathrm{a}}$ Vara da Justiça Federal de Foz do Iguaçu (Paraná).

Mesmo sendo este um estudo de caso, que demandou uma extensa pesquisa de campo, sua generalização requer cautela. Porém, seus resultados podem servir de indicativo para pesquisas futuras, atestando sua veracidade. A revisão de literatura feita sobre religião e crime sinaliza para a complexidade deste tema.

As variáveis do modelo que deram significância estatística e, portanto, podem ser consideradas como influentes na prática religiosa (variável dependente) dessas pessoas que cometeram delitos, antes de terem sido presas e condenadas com penas alternativas, foram: "harmonia familiar", "tem filhos", "religião católica" e "religião evangélica" - relação positiva entre a variável dependente e as variáveis independentes supracitadas; "ensino superior completo", "amasiado", "uso de bebida alcoólica" e "uso de drogas" - relação negativa entre a variável dependente e as variáveis independentes supracitadas. Considerando todas as variáveis do modelo estimado, a probabilidade da prática religiosa para este caso é de 59,5 p.p.

Atestando empiricamente uma pergunta não muito simples, qual seja, se pratica a religião que diz seguir, pois ter uma religião não significa, necessariamente, praticála, é de ser postular um efeito dissuasor desse modus vivendi sobre o crime. Entretanto, não foi isto o constatado. Então o que motiva um(a) praticante de uma determinada religião a entrar para o mundo do crime? Em grande proporção isto ocorreu, e vem ocorrendo conforme outras literaturas consultadas neste artigo, por incentivos de ganho fácil/indução de amigos/cobiça, ambição, ganância/inveja/manter o status/devido interações em grupos sociais que incentivam a prática de uma atividade ilícita etc. Estes fatores, bem como outros de natureza comportamental ou de dificuldade financeira, fizeram com as pessoas pesquisadas no presente estudo, praticantes de uma religião, migrassem para uma atividade ilegal que pudesse lhe render recursos financeiros e/ou materiais para satisfazer suas necessidades e bem-estar. A força da variável pecúnia ante aos valores morais, retratada pelo fato de a expectativa do benefício ser maior do que seu custo (numa atividade ilícita), superou a trava moral consubstanciada na prática de uma determinada religião. Acresce a isto a impunidade frequentemente reinante no Brasil.

Não é sem razão que algumas literaturas apontam para encaixes nas categorias 'fiel' e 'bandido' como não totalmente excludentes. Alguns(mas) bandidos(as) buscam as religiões não somente para se congregarem, mas para formarem uma "rede de proteção" que usa a fé como uma espécie de "fechamento de corpo". Alguns 
delinquentes, ao invés de se apoiarem na religião como trava moral para romper com o ideário criminoso, atrevem-se a usá-la como instrumento de proteção para suas atitudes ilícitas, muitas vezes, de natureza violenta.

Finalizando, fica a sugestão para que novos estudos sejam realizados com o fito de tornar menos complexo este assunto, trazendo elementos que possam clarear, sem achismos, o presente debate.

\section{Fonte de Financiamento}

CNPq-Conselho Nacional de Desenvolvimento Científico e Tecnológico.

\section{Referências}

AMARAL, Josineide A. S. Determinantes da entrada das mulheres no tráfico de drogas: um estudo para o Acre (Brasil). 2019. 148f. Tese (Doutorado em Desenvolvimento Regional e Agronegócio) - Universidade Estadual do Oeste do Paraná, Toledo, 2019.

BECKER, Ana P. S.; MAESTRI, Tânia P.; BOBATO, Sueli T. Impacto da religiosidade na relação entre pais e filhos adolescentes. Arquivos Brasileiros de Psicologia, Rio de Janeiro, vol. 67, n. 1, p. 84-98, 2015.

BECKER, Gary S. Crime and punishment: an economic approach. Journal of Political Economy, vol. 76, n. 1, p. 169-217, 1968.

BERGER, Isis R.; FONSECA, Lívia C. C. da. A língua árabe no contexto plurilíngue de Foz do Iguaçu. Domínios de Lingu@gem, vol. 13, n. 3, p. 9951017, 2019.

BORILLI, Salete P. Análise das circunstâncias econômicas da prática criminosa no Estado do Paraná: estudo de caso nas penitenciárias Estadual, Central e Feminina de Piraquara. 2005. 154f. Dissertação (Mestrado em Desenvolvimento Regional e Agronegócio) - Universidade Estadual do Oeste do Paraná, Toledo, 2005.

BRASIL. Código penal (Lei N. 2.848/1940, de 7 de dezembro de 1940). Publicada no Diário Oficial da União. Disponível em: 
https://www2.camara.leg.br/legin/fed/declei/1940-1949/decreto-lei-2848-7dezembro-1940-412868-publicacaooriginal-1-pe.html. Acesso em: 20 jun. 2021.

BRASIL. Código penal. In: CÉSPEDES, L.; ROCHA, F. D. (Org.) Vade Mecum. 11 ed. São Paulo: Saraiva, 2017. p. 509-553.

BRASIL. Lei N. 9.714/1998, de 25 de novembro de 1998. Publicada no Diário Oficial da União. Disponível em: http://www.planalto.gov.br/ccivil_03/LEIS/L9714.htm. Acesso em: 20 jun. 2021.

CNFCP. Prática religiosa. Brasília: Centro Nacional de Folclore e Cultura Popular, 2021. Disponível em: http://www.cnfcp.gov.br/tesauro/00001061.htm. Acesso em: 18 jun. 2021.

CNPCP. Plano nacional de política criminal e penitenciária. 2020-2023. Brasília: Conselho Nacional de Política Criminal e Penitenciária, 2019. Disponível em: https://www.gov.br/depen/ptbr/composicao/cnpcp/plano_nacional/PNPCP-2020-2023.pdf. Acesso em: 20 jun. 2021.

CUNHA, C. V. "Traficantes evangélicos": novas formas de experimentação do sagrado em favelas cariocas. Plural - Revista de Ciências Sociais, vol. 15, p. 1346, 2008.

DEPEN. Levantamento nacional de informações penitenciárias. Brasília: Departamento Penitenciário Nacional, 2019. Disponível em: http://dados.mj.gov.br/dataset/infopen-levantamento-nacional-de-informacoespenitenciarias. Acesso em: 20 jun. 2021.

FREY, Bruno S. Not just for the money: an economic theory of personal motivation. Cheltenham/UK: Edward Elgar Publishing, 1997.

GIL, Antônio C. Técnicas de pesquisa em economia e elaboração de monografias. São Paulo: Atlas, 2000. 
GONÇALVES JÚNIOR, Carlos A.; SHIKIDA, Pery F. A. Determinantes da reincidência penal no Estado do Paraná: uma análise empírica da economia do crime. Economic Analysis of Law Review, Brasília, vol. 4, n. 2, p. 315-336, 2013.

GUJARATI; Damodar N.; PORTER, Dawn C. Econometria básica. 5 ed. Rio de Janeiro: Elsevier/Campus, 2011.

HEATON, Paul. Does religion really reduce crime? The Journal of Law and Economics, vol. 49, n. 1, p. 147-172, 2006.

HOSMER, David W.; LEMESHOW, Stanley. Applied logistic regression. 2 ed. New York: Wiley Publication, 2000.

IBGE. Religião. Rio de Janeiro: Instituto Brasileiro de Geografia e Estatística, 2010. Disponível em: https://cidades.ibge.gov.br/brasil/pesquisa/23/22107. Acesso em: 18 jun. 2021.

LOUREIRO, Paulo R. A.; MENDONÇA, Mário J. C.; MOREIRA, Tito B. S.; SACHSIDA, Adolfo. Crime, economic conditions, social interactions and family heritage. International Review of Law and Economics, vol. 29, p. 202-209, 2009.

MARQUES, Vagner A. A dupla vida do pesquisador: etnografia da conversão ao pentecostalismo de membros do PCC na zona leste de São Paulo. Revista Eletrônica História em Reflexão, vol. 7, n. 14, p. 1-19, 2013.

MORELLATO, Ana C. B. Tráfico de drogas, acumulação social da violência nas favelas, neopentecostalismo e a expressão de fé pelos "traficantes evangélicos”. 2019. 42f. Monografia (Graduação em Direito) - Faculdade de Direito de Vitória, Vitória, 2019.

MURTA, Susanne R.; ARAUJO JUNIOR, Ari F.; SHIKIDA, Cláudio D. Religião e criminalidade no Brasil: primeiras evidências sob enfoque econômico. Textos de Economia, Florianópolis, vol. 11, n. 2, p. 90-107, 2008. 
O QUE É AMASIADO? Disponível em: https:// escolaeducacao.com.br/o-quee-amasiado. Acesso em: 20 jun. 2021.

OLINI, Rafael. M.; DANIEL, Lindomar P.; DALFOVO, Wylmor C. T.; ORLANDI, Marines; SHIKIDA, Pery F. A. Homicídio e desigualdade de renda: uma análise espacial para o Estado de Mato Grosso em 2000 e 2010. Economic Analysis of Law Review, Brasília, vol. 9, p. 107-130, 2019.

RIBEIRO, Fernanda M. L; MINAYO, Maria C. de S. O papel da religião na promoção da saúde, na prevenção da violência e na reabilitação de pessoas envolvidas com a criminalidade: revisão de literatura. Ciência \& Saúde Coletiva, vol. 19, n. 6, p. 1773-1789, 2014.

SANTOS, Camila R. S. A influência da religiosidade e das práticas religiosas, mediadas pela personalidade, na atuação do indivíduo no contexto organizacional. 2020. 130f. Tese (Doutorado em Administração) - Universidade Federal de Pernambuco, Recife, 2020.

SANTOS, Mário M.; NEVES, Fabiana, J. T.; GOUVEIA, M. Liberdade religiosa no brasil e sua fundamentação constitucional. II Encontro de Iniciação

Científica e I Encontro de Extensão Universitária, vol. 2, n. 2, p. 1-10, 2006.

SCHLEMPER, Alexandre L. Economia do crime: uma análise para jovens criminosos no Paraná e Rio Grande do Sul. 2018. 164f. Tese (Doutorado em Desenvolvimento Regional e Agronegócio) - Universidade Estadual do Oeste do Paraná, Toledo, 2018.

SHIKIDA, Cláudio D.; ARAUJO JUNIOR, Ari F.; SHIKIDA, Pery F. A. A moral importa? Revista de Economia e Administração, São Paulo, vol. 4, n. 4, p. 415-426, 2005.

SHIKIDA, Pery F. A. Economia do crime: teoria e evidências empíricas a partir de um estudo de caso na Penitenciária Estadual de Piraquara (PR). Revista de Economia e Administração, São Paulo, vol. 4, n. 3, p. 315-342, 2005. 
SHIKIDA, Pery F. A. Considerações sobre economia do crime no Brasil: um sumário de 10 anos de pesquisa. Revista de Análise Econômica do Direito, Brasília, vol. 1, n. 2, p. 318-336, 2010.

SHIKIDA, Pery F. A. Uma análise da economia do crime em estabelecimentos penais paranaenses e gaúchos: o crime compensa? Revista Brasileira de Execução Penal (RBEP), Brasília, vol. 1, n. 1, p. 257-278, 2020.

SILVA, Rogério R. Espiritualidade e religião no trabalho: possíveis implicações para o contexto organizacional. Psicologia Ciência e Profissão, Brasília, vol. 28, n. 4. p. $768-779,2008$.

WOOLDRIDGE, Jeffrey M. Introdução à econometria: uma abordagem moderna. 6 ed. São Paulo: Pioneira Thomson Learning, 2017.

YIN, Robert K. Estudo de caso: planejamento e métodos. 5 ed. Porto Alegre: Bookman, 2015. 
Data de submissão: 20/04/2020

Data de aprovação: 22/06/2021

Revisão: Daniela Matthes (português), Anderson de Miranda Gomes (inglês) e Yanet María Reimondo Barrios (espanhol).

Pery Francisco Assis Shikida

Programa de Pós-Graduação em Desenvolvimento Regional e Agronegócio /

Universidade Estadual do Oeste do Paraná

Rua da Faculdade, 645 - Jardim Santa Maria

85903-000 Toledo/PR, Brasil

Orcid: http://orcid.org/0000-0001-9621-1520

E-mail:peryshikida@hotmail.com

\section{Helena Nickel}

Bacharela em Direito e mestre em Desenvolvimento Regional e Agronegócio

Largo São Vicente de Paulo, 1085

85900-215 Toledo/PR, Brasil

Orcid: http://orcid.org/0000-0002-8061-9414

E-mail: jasaeconomia@hotmail.com

Josineide Aquino da Silva Amaral

Centro de Ciências Sociais Aplicada / Universidade Federal do Acre

Rodovia BR 364, km 4 - Distrito Industrial

69920-900 Rio Branco/AC, Brasil

Orcid: http://orcid.org/0000-0002-0587-2321

E-mail: jasaeconomia@hotmail.com 